\title{
ACQUIRED IMMUNITY AGAINST MOUSE TYPHOID: GENETIC RESTRICTION AND COMPARATIVE EFFICACY OF RIBOSOMAL AND CONVENTIONAL VACCINES
}

\author{
A. D. Nickol AND P. F. Bonventre \\ Department of Microbiology, University of Cincinnati Medical Center, Cincinnati, \\ Ohio 45267, USA
}

SummaRY. Strains of mice immunised with a ribosomal preparation of Salmonella typhimurium varied in their ability to survive an intraperitoneal challenge of virulent $S$. typhimurium. Immunised nude (nu/nu), heterozygous $(\mathrm{nu} /+)$ mice, strain $\mathrm{C} 57 \mathrm{Bl} / 6 \mathrm{~J}$ and strain $\mathrm{CBA} / \mathrm{J}$ succumbed to lethal infection whereas strains $\mathrm{C} 3 \mathrm{D} 2 \mathrm{~F}_{1} / \mathrm{J}, \mathrm{B} 6 \mathrm{D} 2 \mathrm{~F}_{1} / \mathrm{J}$ and $\mathrm{A} / \mathrm{J}$, and Swiss mice were fully protected. Strains $\mathrm{DBA} / 2 \mathrm{~J}$ and $\mathrm{C} 3 \mathrm{H} / \mathrm{HeJ}$ were partially protected.

Enumeration of the systemic bacterial population after challenge with $S$. typhimurium indicated that all immunised mouse strains were able to reduce the infectious load. $S$. typhimurium was rapidly inactivated in the peritoneal cavity of immunised mice, effectively reducing the challenge and thereby limiting the number of organisms available to seed the systemic circulation. This response was also obtained in immunised athymic mice and was therefore attributed to a $T$-cell independent antibody response. Organisms that escaped destruction in the peritoneal cavity multiplied rapidly in the reticuloendothelial organs. Only mice from strains genetically capable of developing an effective cell-mediated immune response to the antigenic stimulus provided by the challenge organism itself survived infection.

The efficacy of ribosomal immunisation was compared with immunisation by heat-killed bacteria, viable attenuated and viable virulent organisms by enumeration of the systemic bacterial population after intravenous challenge with $S$. typhimurium. Vaccination with ribosomal preparations or heat-killed organisms provided limited protection whereas immunity provided by viable organisms was far superior.

\section{INTRODUCTION}

Salmonella typhimurium infection in the mouse is a good experimental model for human typhoid (Mackaness, Blanden and Collins, 1966). Immunity against mouse typhoid follows recovery from infection (Hobson, 1957; Mitsuhashi et al., 1958; Jenkin and Rowley, 1963; Mackaness et al., 1966; Collins, 1971), vaccination with attenuated, antigenically similar salmonella serotypes (Collins, Mackaness and Blanden, 1966; Collins, 1968; Germanier, 
1972), or administration of killed organisms together with Freund's complete adjuvant (Collins, 1972, 1973). The protection afforded by these preparations has been ascribed to their capacity to engender specific cell-mediated immunity in the murine host (Collins, 1974). In contrast, killed bacterial vaccines administered without adjuvant protect mice to a lesser degree because they induce only an antibody response (Collins, 1974). Adaptation of methods utilising viable attenuated organisms or adjuvants for vaccination of man is complicated by actual and potential adverse effects (Collins, 1974). Observations that ribosomes isolated from $S$. typhimurium protected mice against large challenge inocula (Venneman and Bigley, 1969; Venneman, Bigley and Berry, 1970; Johnson, 1972) led to the suggestion that a protective, nontoxic, subcellular vaccine could be developed. The appearance of circulating (Venneman and Berry, 1971a; Eisenstein, 1975; Lin and Berry, 1978) and cytophilic antibodies (Margolis and Bigley, 1972) in response to immunisation with ribosomal preparations of $S$. typhimurium has been demonstrated. Other studies (Venneman and Berry, 1971 b; Smith and Bigley, 1972) have suggested a role for cell-mediated immunity as a basis for the protective immunity observed and thus the relative importance of each arm of the immune response in providing protection remains a matter of controversy.

In previous studies of the efficacy of $S$. typhimurium ribosomal vaccines outbred mice were used. Inbred strains vary in native susceptibility to infection with S. typhimurium (Robson and Vas, 1972; Plant and Glynn, 1974) and in their responses to salmonella vaccines (Robson and Vas, 1972; Misfeldt and Johnson, 1976). Natural resistance and the capacity to develop specific protective immunity appear to be under complex genetic control but unrelated to the H-2 histocompatibility complex (Robson and Vas, 1972; Plant and Glynn, 1976).

We report the results of studies designed to ascertain the type and quality of protective immunity induced by vaccination with a ribosomal preparation derived from S. typhimurium. A comparison is made of the immunity induced by the ribosomal vaccine in several inbred and outbred strains of mice, and the quality of this immunity is compared with that provided by more conventional viable and nonviable whole-cell vaccines.

\section{MATERIALS AND METHODS}

Animals. Mice, strains C57Bl/6J, CBA/J, C3H/HeJ, DBA/2J, A/J, C3D2F $/ \mathrm{J}(\mathrm{C} 3 \mathrm{H} / \mathrm{HeJ}$ ㅇ

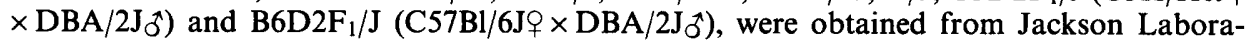
tories, Bar Harbor, Maine. Randomly bred Swiss-Cox mice were obtained from Laboratory Supply Co., Indianapolis, Indiana. Athymic nude (nu/nu) and heterozygote (nu/ +) littermates of Balb/c genetic background were bred in the animal house at the University of Cincinnatti Medical Center as described previously (Nickol and Bonventre, 1977). Female mice, 6-10 weeks of age were used in all experiments.

Micro-organisms. The virulent S. typhimurium strain SR-11 was obtained from Dr W. Johnson, University of Iowa Medical Center, Iowa City, Iowa. S. typhimurium strain SR-11 $\mathrm{Sm}^{\mathrm{R}}$ is a streptomycin-resistant mutant derived from strain SR-11 under selective pressure during growth in antibiotic-containing culture medium. Strain $\mathrm{Sm}^{\mathrm{R}}$ was slightly less virulent than the parent SR-11 strain as measured by LD50 titrations in Swiss-Cox mice. The 
attenuated S. typhimurium strain RIA was obtained from Dr L. J. Berry, University of Texas, Austin, Texas. Both strains were initially grown in brain-heart infusion (BHI) broth and stored in separate portions at $-70^{\circ} \mathrm{C}$. For each experiment, a frozen stock culture was used to seed 50 $\mathrm{ml}$ of BHI broth. Streptomycin at a concentration of $100 \mu \mathrm{g} / \mathrm{ml}$ was included in the growth medium when strain SR-11 Sm ${ }^{\mathrm{R}}$ was used. After aerobic incubation for $3 \mathrm{~h}$ at $37^{\circ} \mathrm{C}$, cultures were harvested and adjusted to appropriate concentrations for mouse challenge as described previously (Nickol and Bonventre, 1977).

Vaccines and vaccination. In the preliminary studies, S. typhimurium strain SR-11 ribosomal vaccine was provided by Dr W. Johnson, University of Iowa Medical Center. Subsequently, ribosomal preparations were prepared from $S$. typhimurium strain SR-11 according to the method of Johnson (1973). The protein content of the vaccine was determined by the method of Lowry et al. (1951), while RNA and DNA were measured by the orcinol (Ashwell, 1957) and diphenylamine (Dische, 1955) procedures respectively with bovine serum albumin (Sigma Chemical Co.), yeast RNA (Nutritional Biochemical Corp.) and salmon-sperm DNA (Calbiochem) as standards. The vaccine protein:RNA:DNA ratio by weight averaged 60:40:0.2. The standard vaccinating dose per mouse administered intraperitoneally was adjusted to that quantity of vaccine containing $100 \mu \mathrm{g}$ of ribosomal protein.

Heat-killed $S$. typhimurium strain SR-11 was prepared by heating a suspension of the organisms in phosphate-buffered saline (PBS, $4 \times 10^{8}$ bacteria/ml) at $70^{\circ} \mathrm{C}$ for $1 \mathrm{~h}$. The suspension was diluted in PBS and mice were given intraperitoneal injection of $2.0 \times 10^{7}$ killed organisms. Immunised animals were challenged 2 weeks after vaccination.

Calculation of LD50 and mean time to death. Groups of five mice were given intraperitoneal or intravenous challenge of $0.2 \mathrm{ml}$ of tenfold dilutions prepared from a standard suspension of $S$. typhimurium strain SR-11. The $50 \%$ lethal dose (LD50) values were calculated after 30 days by the method of Reed and Muench (1938). Groups of 10-30 mice were given intraperitoneal injection of $0.2 \mathrm{ml}$ of a suspension of $S$. typhimurium SR-11. Mean time to death (MTTD) was calculated for each group over a 30-day period.

Enumeration of viable bacteria. Viable bacteria in the spleen, liver, blood and peritoneal cavity were counted as colony-forming units (cfu) at intervals after bacterial challenge. Inocula and time intervals at which viable bacteria were determined varied for each experiment as described in the text.

Mice were killed by cervical dislocation. The spleen and a portion of liver were excised, weighed, and homogenised as a $10 \%(\mathrm{w} / \mathrm{v})$ suspension in sterile BHI broth. Tenfold dilutions were plated on BHI agar and colonies were counted after incubation for $48 \mathrm{~h}$ at $37^{\circ} \mathrm{C}$. The values presented are the geometric means expressed as $\log _{10} \mathrm{cfu} / 100 \mathrm{mg}$ of tissue. Bacteria in blood were counted on BHI agar by plating appropriate dilutions of samples obtained by cardiac puncture as described above. Bacteria in the peritoneal cavity were counted by injecting $5 \mathrm{ml}$ of cold sterile PBS into the peritoneal cavity followed by gentle abdominal massage for $1 \mathrm{~min}$. Fluid was withdrawn aseptically and sonicated for $10 \mathrm{~s}$ at a power setting of $10 \mathrm{~W}$ on a Bronson Sonifier (model W140). This procedure disrupted macrophages without reduction of bacterial viability.

\section{RESULTS}

\section{Protection of mice with $S$. typhimurium ribosomal vaccine}

LD50 titrations revealed no significant differences in the natural resistance of the several strains when challenged by the peritoneal route. The LD50 for the virulent SR-11 strain was less than 10 organisms for all inbred mouse strains tested. The LD50 for random-bred Swiss-Cox mice was between 10 and 100 organisms.

Mice of each strain were immunised with a standard dose of the ribosomal vaccine administered intraperitoneally and they were challenged intraperi- 
toneally 14 days later with either 50 or 500 viable units of $S$. typhimurium (i.e., 5-50 LD50). The 30-day mortality values of vaccinated mice are shown in table 1. Vaccinated mice can be arbitrarily divided into three groups on the basis of survival after intraperitoneal challenge. The Balb/c athymic $(\mathrm{nu} / \mathrm{nu})$, Balb/c heterozygote $(\mathrm{nu} /+), \mathrm{C} 57 \mathrm{Bl} / 6 \mathrm{~J}$, and $\mathrm{CBA} / \mathrm{J}$ strains were not protected by vaccination whereas the $\mathrm{C} 3 \mathrm{D} 2 \mathrm{~F}_{1} / \mathrm{J}, \mathrm{B} 6 \mathrm{D} 2 \mathrm{~F}_{1} / \mathrm{J}, \mathrm{A} / \mathrm{J}$, and Swiss mice were fully immune. Mice of strains $\mathrm{C} 3 \mathrm{H} / \mathrm{HeJ}$ and $\mathrm{DBA} / 2 \mathrm{~J}$ were partially immune.

Unprotected strains, however, were not totally unresponsive to the ribosomal vaccine. The MTTD values of normal and vaccinated mice of each strain challenged with 500 virulent organisms are also given in table I. A

TABLE I

Mortality and mean time till death of mice challenged intraperitoneally with Salmonella typhimurium SR-11 2 weeks after vaccination with an homologous ribosomal preparation

\begin{tabular}{|c|c|c|c|c|}
\hline \multirow{2}{*}{$\begin{array}{l}\text { Mouse } \\
\text { strain }\end{array}$} & \multicolumn{2}{|c|}{$\begin{array}{l}\text { Percentage mortality } \\
\text { after challenge of }\end{array}$} & \multicolumn{2}{|c|}{$\begin{array}{l}\text { Mean time till death } \\
\text { (days } \pm \text { SEM) for }\end{array}$} \\
\hline & 50 LD50 & 500 LD50 & nonimmunised mice & immunised mice \\
\hline $\begin{array}{l}\text { Balb/c (nu/nu) } \\
\text { Balb/c (nu/t) } \\
\text { C57BL/6J } \\
\text { CBA/J }\end{array}$ & $\begin{array}{c}100 \\
100 \\
\cdots \\
\cdots\end{array}$ & $\begin{array}{c}100 \\
\ldots \\
100 \\
100\end{array}$ & $\begin{array}{l}6.2 \pm 0.6 \\
4.5 \pm 0.2 \\
4.7 \pm 0.2 \\
3.8 \pm 0.3\end{array}$ & $\begin{array}{r}8 \cdot 1 \pm 1 \cdot 1 \\
8 \cdot 7 \pm 0.8 \\
8 \cdot 6 \pm 0.6 \\
15 \cdot 4 \pm 1 \cdot 5\end{array}$ \\
\hline $\begin{array}{l}\mathrm{C} 3 \mathrm{H} / \mathrm{HeJ} \\
\mathrm{DBA} / 2 \mathrm{~J}\end{array}$ & $\begin{array}{l}73 \\
20\end{array}$ & $\begin{array}{l}98 \\
58\end{array}$ & $\begin{array}{l}4 \cdot 5 \pm 0 \cdot 3 \\
9 \cdot 0 \pm 0 \cdot 7\end{array}$ & $\begin{array}{l}15 \cdot 3 \pm 0.9 \\
14 \cdot 2 \pm 0.7\end{array}$ \\
\hline $\begin{array}{l}\mathrm{C} 3 \mathrm{D}_{2} \mathrm{~F}_{1} / \mathrm{J} \\
\mathrm{B} 6 \mathrm{D}_{2} \mathrm{~F}_{1} / \mathrm{J} \\
\mathrm{A} / \mathrm{J} \\
\text { Swiss-Cox }\end{array}$ & $\begin{array}{l}0 \\
0 \\
0 \\
0\end{array}$ & $\begin{array}{l}3 \\
0 \\
0 \\
0\end{array}$ & $\begin{array}{r}8.2 \pm 0.5 \\
12.0 \pm 0.4 \\
8.8 \pm 0.7 \\
10.9 \pm 0.7\end{array}$ & $\begin{array}{l}\cdots \\
\cdots \\
\cdots \\
\cdots\end{array}$ \\
\hline
\end{tabular}

significant extension of the MTTD was noted for all vaccinated mice including strains that, by the LD50 assay, were designated as unprotected. Survival times suggested differences in the native susceptibility of genetically diverse strains to mouse typhoid. The data also show a correlation between the MTTD of unvaccinated animals and the degree of protection afforded by vaccination with the ribosome preparation.

\section{Growth kinetics of $S$. typhimurium strain $S R-11$ in normal and vaccinated strains of mice}

Simple mortality statistics were insufficient to explain the causes for the variable responses of ribosome-vaccinated strains of mice to challenge with $S$. typhimurium. To give more meaningful information, the kinetics of $S$. typhimurium SR-11 infection were monitored in the spleen of normal and vaccinated strains of mice. Two weeks after intraperitoneal administration of $100 \mu \mathrm{g}$ of ribosomal vaccine, mice were challenged intraperitoneally with $10^{3}$ 
S. typhimurium strain SR-11. At intervals after infection the number of viable $S$. typhimurium in the spleen was determined.

The growth kinetics of $S$. typhimurium strain SR-11 in the spleen of unvaccinated mice are presented in fig. 1. The characteristic kinetics of infection in each mouse strain illustrate the subtle variations of natural resistance suggested by MTTD values (table I). The infection kinetics in vaccinated mice are presented in figs. 2 and 3 . All ribosome-vaccinated mice, including strains not protected by vaccination, show a common initial antibacterial response. In all instances, between 2 and $3 \log _{10}$ fewer viable $S$. typhimurium were recovered $24 \mathrm{~h}$ after infection from the spleen of vaccinated mice than those from the spleen of unvaccinated controls. After this initial clearance, the kinetics of infection became distinctive for each strain of mice.

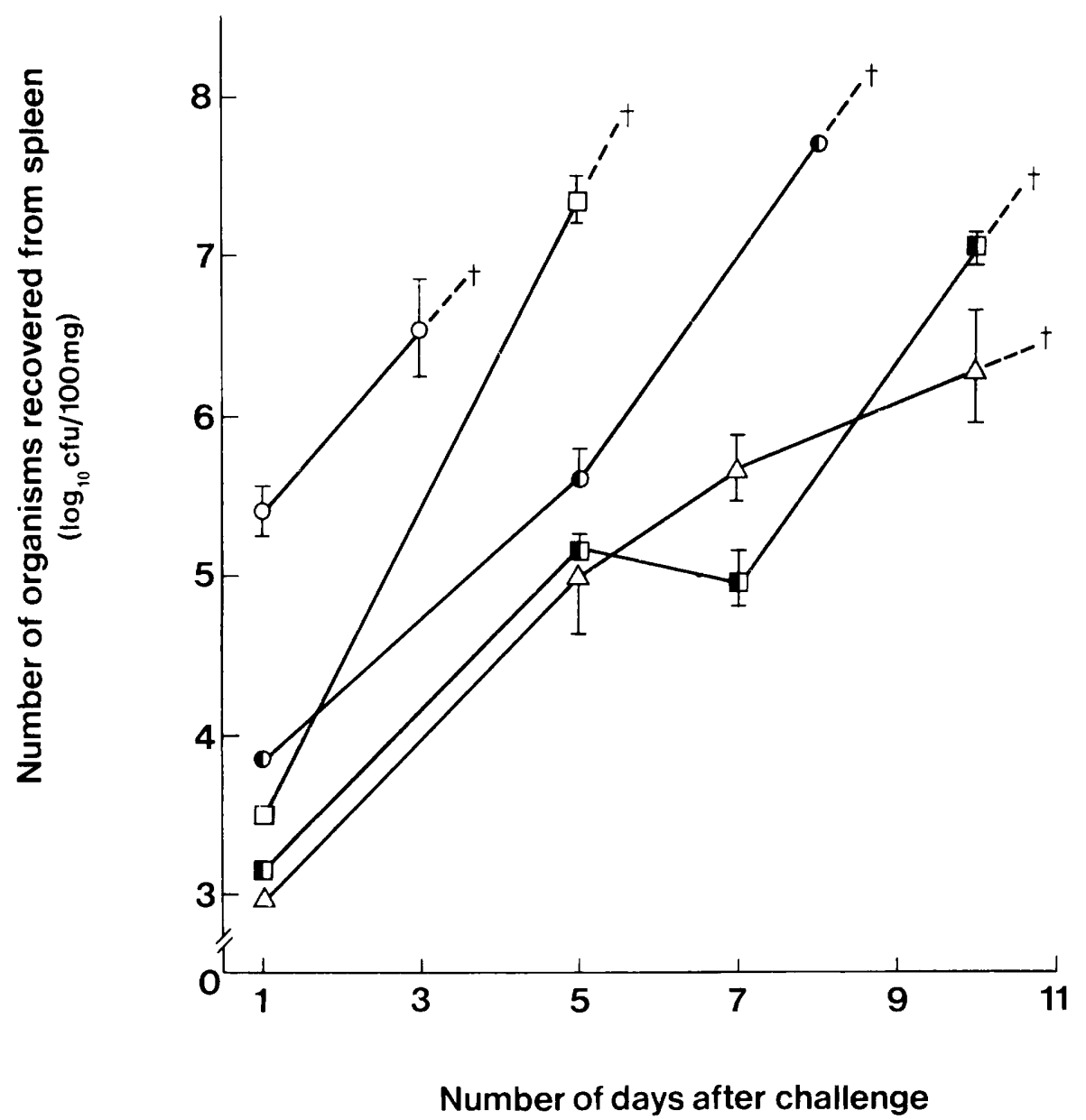

FIG. 1.-Kinetics of Salmonella typhimurium strain SR-11 infection in the spleen of unvaccinated inbred and hybrid mouse strains challenged intraperitoneally with $1.0 \times 10^{3}$ organisms. Mouse strains: $0-0=$ $\mathrm{C} 3 \mathrm{H} / \mathrm{HeJ} ; \square-\mathrm{Q}=\mathrm{C} 57 \mathrm{Bl} / 6 \mathrm{~J} ; \Delta \longrightarrow \Delta=\mathrm{DBA} / 2 ; \mathrm{O} \longrightarrow=\mathrm{C} 3 \mathrm{D}_{2} \mathrm{~F}_{1} / \mathrm{J} ; \mathbf{0} \longrightarrow=\mathrm{B} 6 \mathrm{D} 2 \mathrm{~F}_{1} . \dagger=$ Subsequent death. Values presented are the geometric means of data from three mice \pm SEM. 


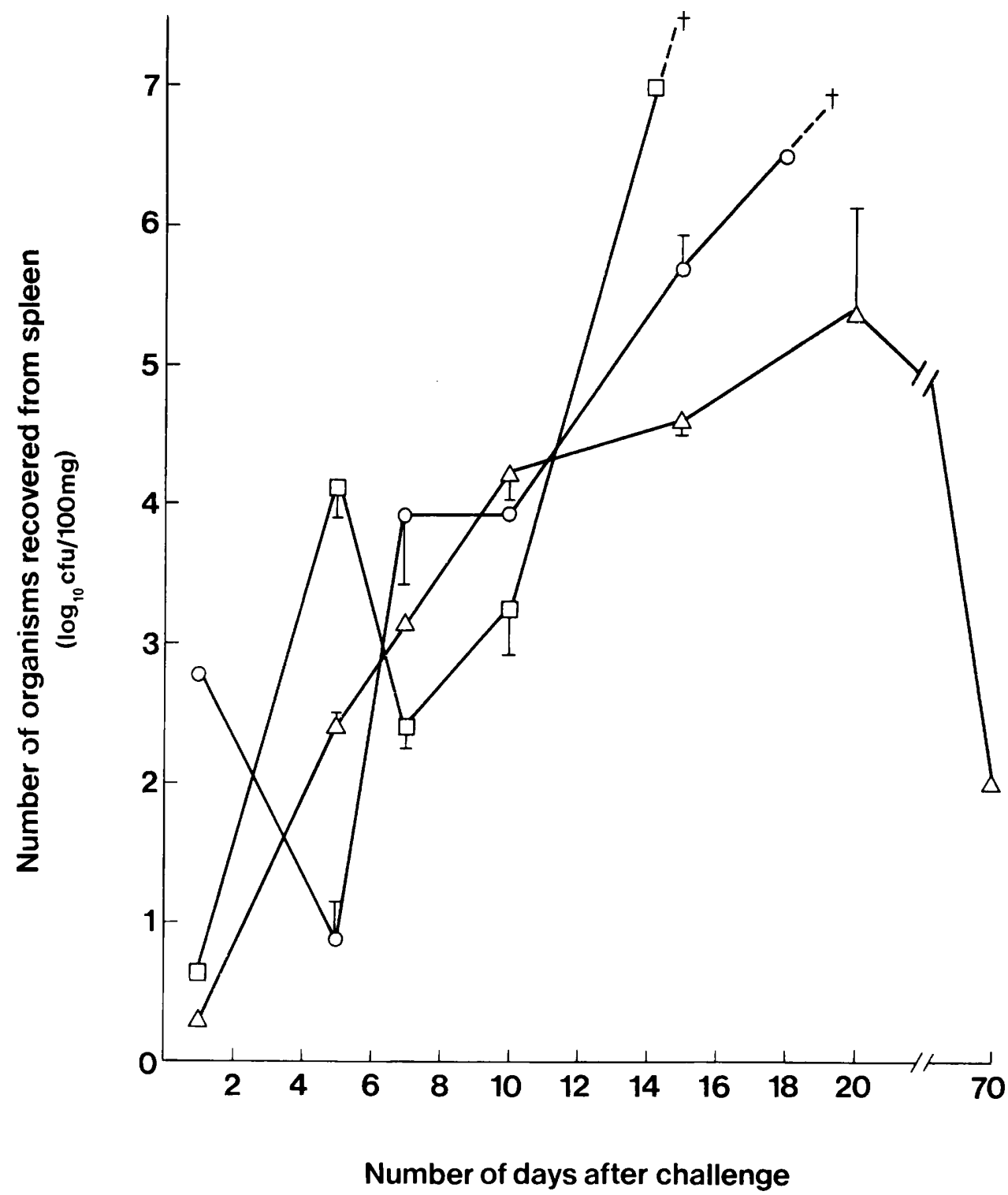

FIG. 2.-Kinetics of Salmonella typhimurium infection in the spleen of inbred mice immunised with a ribosomal vaccine. Mice were immunised intraperitoneally with a ribosomal preparation containing $100 \mu \mathrm{g}$ ribosomal protein and challenged intraperitoneally 2 weeks later with $1.0 \times 10^{3} \mathrm{~S}$. typhimurium strain SR-11. Mouse strains: $0-0=\mathrm{C} 3 \mathrm{H} / \mathrm{HeJ} ; \square-a=\mathrm{C} 57 \mathrm{Bl} / 6 \mathrm{~J} ; \Delta-\Delta=\mathrm{DBA} / 2 \mathrm{~J}$. $\dagger=$ Subsequent death. Values are the geometric means of data from three mice $\pm \mathrm{SEM}$.

In general, the number of viable $S$. typhimurium in the spleen increased during the following 10-14 days of infection. During this period, only mouse strains developing sufficient immunity to induce a chronic infection survived. Organisms were eventually cleared from the spleen of the surviving animals.

Rapid early bactericidal activity. The major response common to all 


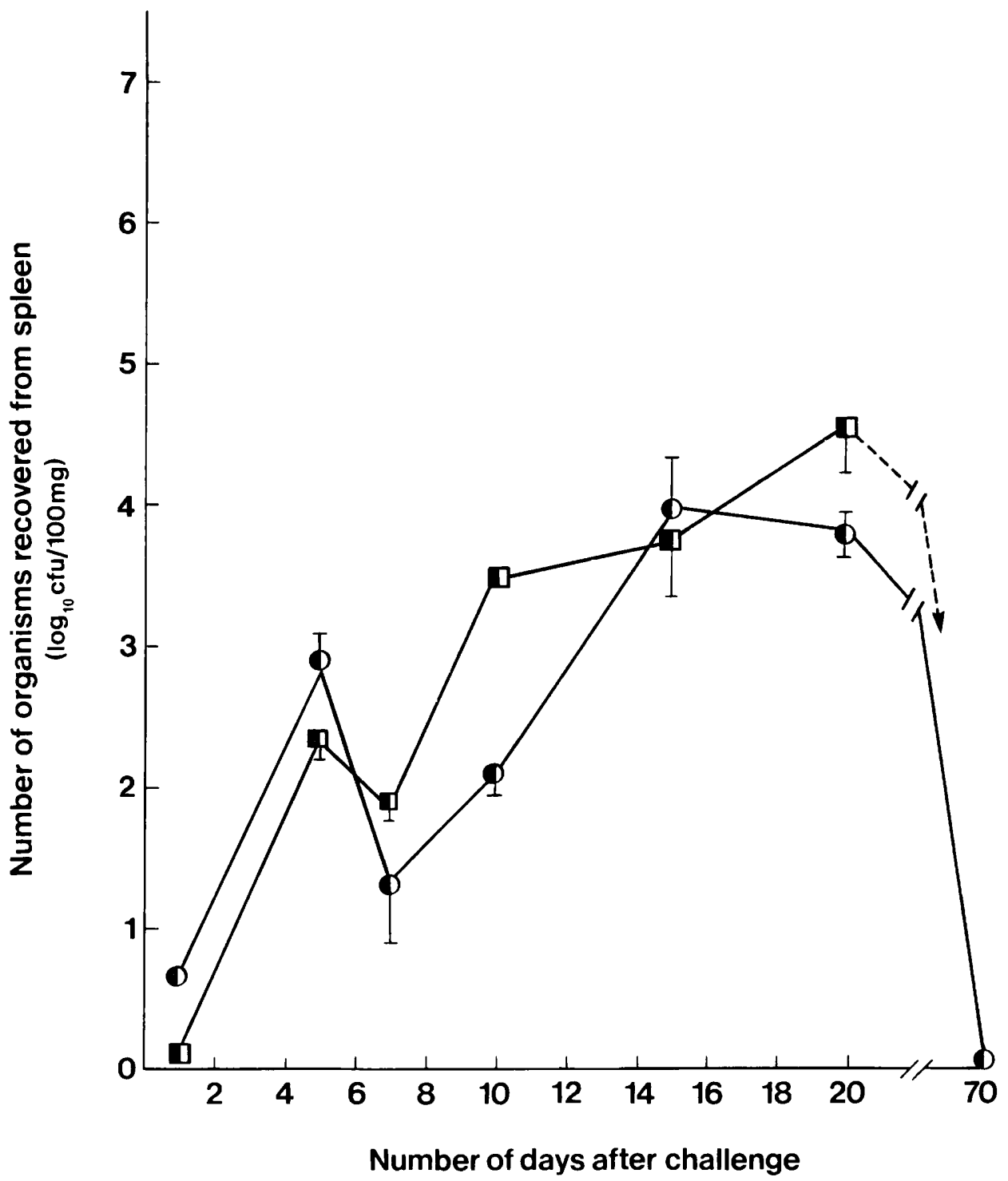

FlG. 3.-Kinetics of $S$. typhimurium infection in the spleen of hybrid mouse strains: $0=\mathrm{C} 3 \mathrm{D} 2 \mathrm{~F}_{1} \mathrm{~J}$; $\mathbf{v}=\mathrm{B}_{62 \mathrm{DF}} \mathrm{J}$. Other details as in fig. 2 .

infected vaccinated mice led to the recovery of significantly fewer viable bacteria from the spleen $24 \mathrm{~h}$ after infection than from the spleen of unvaccinated controls (figs. 1-3). Figs. 4A and 4B illustrate the early bactericidal events in ribosome-vaccinated Swiss-Cox and athymic Balb/c mice after challenge with $S$. typhimurium. Swiss-Cox mice were challenged intraperitoneally with $2.3 \times 10^{4}$ and nude mice with $1.6 \times 10^{2} S$. typhimurium intraperitoneally 2 weeks after ribosomal vaccination. After $4 \mathrm{~h}$, immunised mice of both strains had destroyed more than $99 \%$ of the bacterial challenge 


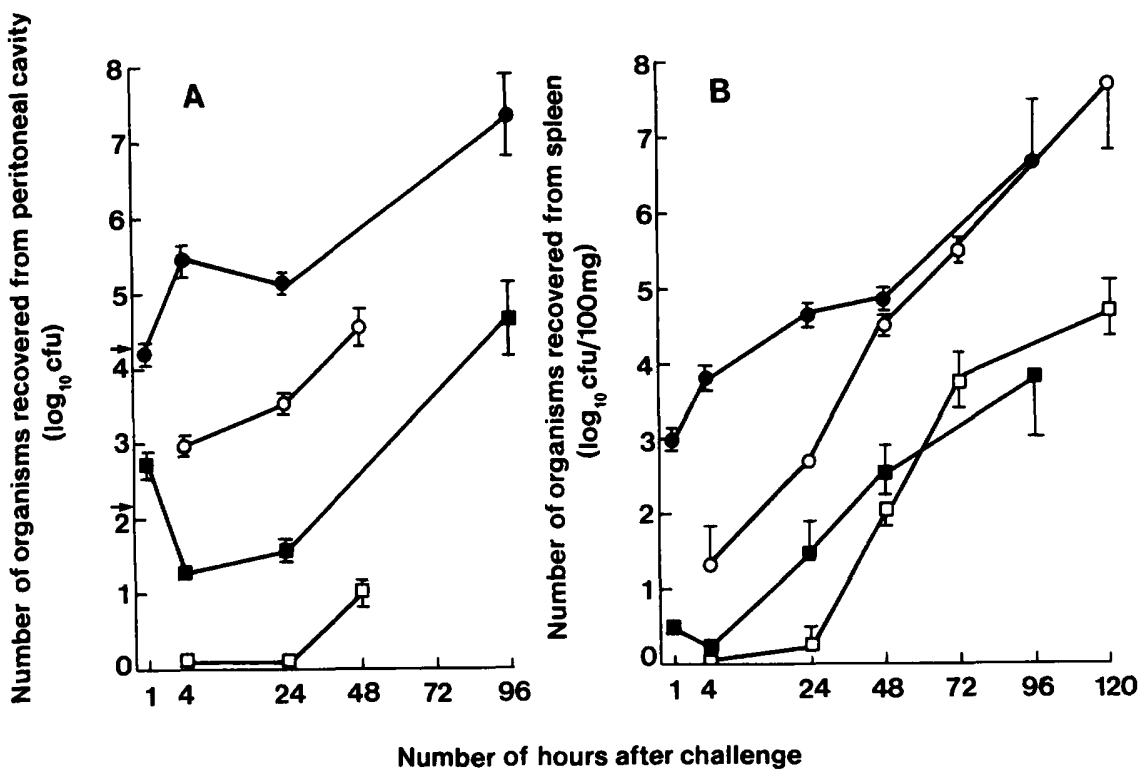

FIG. 4.-Kinetics of Salmonella typhimurium strain SR-11 infection in the peritoneal cavity (A) and spleen (B) of unimmunised and immunised Swiss-Cox and athymic (Balb/c) mice. Immunised animals received a ribosomal preparation containing $100 \mu \mathrm{g}$ of ribosomal protein intraperitoneally 2 weeks before challenge. Swiss-Cox mice were challenged with $2.3 \times 10^{4}$ and athymic mice with $1.6 \times 10^{2} S$. typhimurium intraperitoneally. Mouse strains: $\square-0=$ unimmunized athymic; $\square-\square=\mathrm{im}$ munised athymic; $\longrightarrow=$ unimmused Swiss-Cox; $\longrightarrow=$ immunised Swiss-Cox.

within the peritoneal cavity (fig. 4A). The bacterial challenge, however, was not reduced in the peritoneal cavity of unvaccinated mice, thus enabling large numbers of bacteria to seed the systemic circulation (fig. 4B). The migration of viable bacteria in large numbers to the spleen of immunised mice was delayed as a result of the small population of bacteria surviving phagocytosis and killing in the peritoneal cavity. The similarities in the antibacterial response of vaccinated T-cell-deficient and immunocompetent mice suggests a major role for antibody rather than cell-mediated immunity in the bactericidal activity generated by ribosomal vaccination.

\section{Effect of route of immunisation and challenge}

All previous studies except one (Medina, Vas and Robson 1975), employed the intraperitoneal route of challenge for investigation of the efficiency of salmonella ribosomal vaccines. We have shown that the extensive killing of $S$. typhimurium that takes place in the peritoneal cavity of ribosome-vaccinated mice effectively reduces the inoculum and thereby delays or restricts the onset of systemic infection. This phenomenon has been observed previously after vaccination with other nonviable preparations (Ushiba et al., 1959). S. typhimurium introduced by the natural route, i.e., orally, would not encounter this antibacterial environment early in the infection. Therefore, we compared the protection afforded by ribosomal vaccination of Swiss mice against 
intraperitoneal challenge with that against intravenous challenge (table II). Unimmunised mice were found to be 100 times more resistant to challenge by the intravenous route. However, the ribosomal vaccine engendered a protective index of only $2 \log _{10}$ units when mice were challenged intravenously as compared with a protection greater than $5 \log _{10}$ when the mice were challenged by the intraperitoneal route. This clearly illustrates that, as is the case for other nonviable vaccines (Blanden, Mackaness, and Collins, 1966), intraperitoneal challenge of immunised mice with $S$. typhimurium artificially potentiates the actual protective capacity of the ribosomal vaccine. Intravenous immunisation with the ribosomal preparation provided the same degree of protection as that observed after intraperitoneal immunisation.

TABLE II

Effect of route of immunisation with ribosomal vaccine and challenge with $S$. typhimurium strain $S R-11$ in Swiss-Cox mice

\begin{tabular}{cc|c}
$\begin{array}{c}\text { Route of } \\
\text { challenge }\end{array}$ & $\begin{array}{c}\text { Route of } \\
\text { immunisation }\end{array}$ & $\begin{array}{c}\text { LD50 } \\
\text { (cfu) }\end{array}$ \\
\hline IP & NI & $3.0 \times 10^{1}$ \\
IP & IP & $>2.4 \times 10^{6}$ \\
IP & IV & $>2.4 \times 10^{6}$ \\
IV & NI & $3.5 \times 10^{3}$ \\
IV & IP & $5.4 \times 10^{5}$ \\
IV & IV & $2.0 \times 10^{5}$ \\
\hline
\end{tabular}

\section{Comparison of protection engendered by vaccines}

The protection provided by the ribosomal preparations was compared with the protection afforded by a heat-killed preparation, a live attenuated organism (strain RIA) and a sublethal dose of viable virulent $S$. typhimurium strain SR-11 $\left(<10^{2}\right)$. Two weeks after vaccination with one of these preparations, Swiss-Cox mice were challenged intravenously with $8.4 \times 10^{4} \mathrm{~S}$. typhimurium strain SR-11 Sm${ }^{\mathrm{R}}$. Streptomycin resistance allowed the challenge organism to be distinguished from the viable strain used for vaccination. At intervals blood, spleen and liver were assayed for their bacterial content. A major portion of the challenge inoculum was rapidly cleared from the blood (data not shown) and was inactivated in the reticuloendothelial organs of all vaccinated mice. Despite the persistence of the vaccinating organism, animals immunised by infection with the virulent strain continued to clear the challenge organism from the liver (fig. 5) and spleen (data not shown) for 3 days, after which organisms could be detected only in extremely low numbers and they were cleared within 2 weeks. Residual viable organisms were not observed at the time of challenge in the organs of mice immunised with the attenuated RIA strain. The challenge inoculation in RIA-immunised mice developed into a low-level infection which was eventually cleared. In both groups of animals 


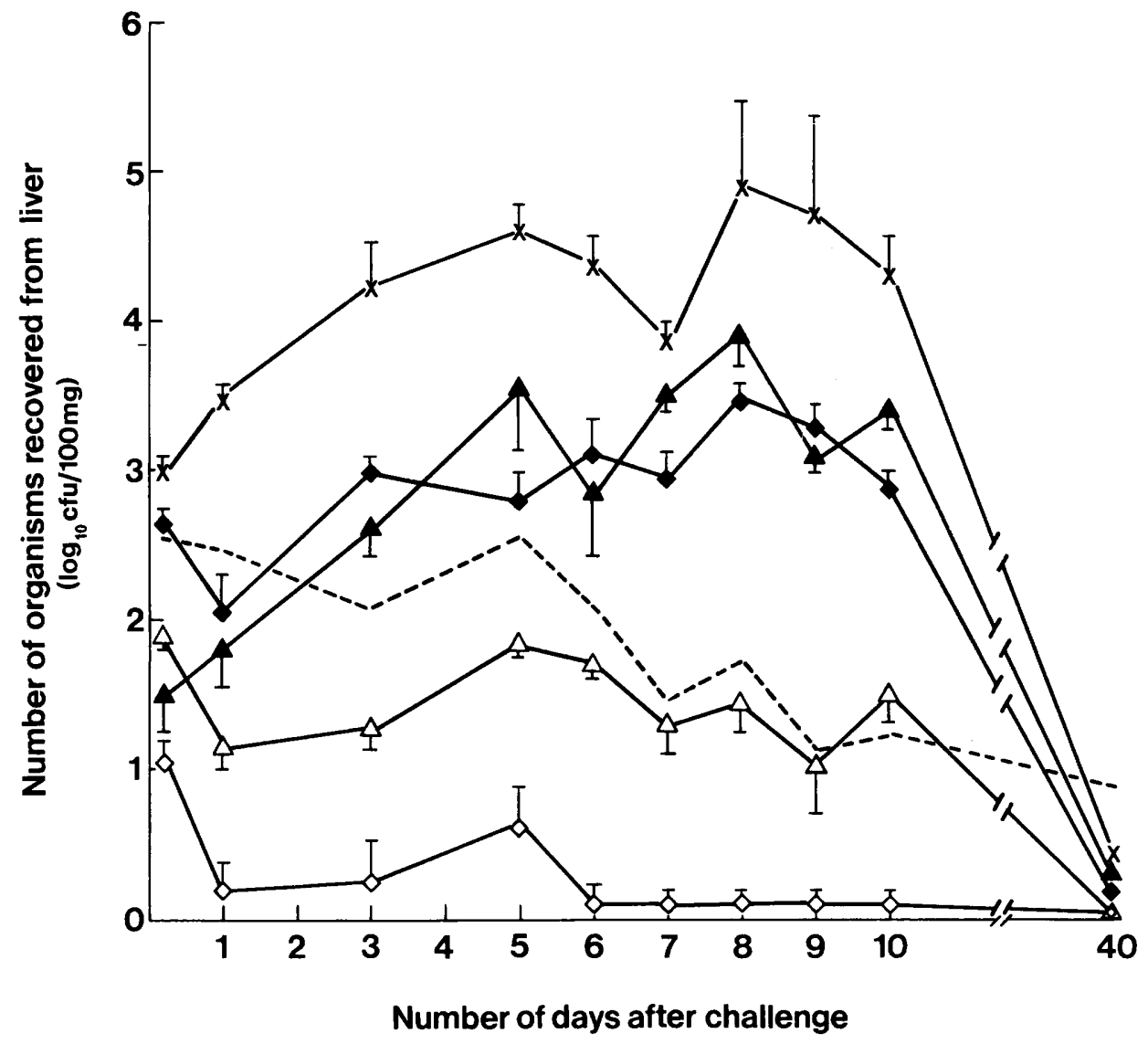

FIG. 5.-Kinetics of Salmonella typhimurium strain SR-11 Sm ${ }^{\mathrm{R}}$ infection in the liver of Swiss-Cox mice challenged intravenously 2 weeks after immunisation with one of several vaccines. Mice were immunised with either $2.0 \times 10^{7}$ heat-milled S. typhimurium strain SR-11 intraperitoneally, a ribosomal preparation containing $100 \mu \mathrm{g}$ of ribosomal protein intraperitoneally, or $5 \times 10^{5}$ viable attenuated $S$. typhimurium strain SR-11 intravenously. The challenge was $8.4 \times 10^{4} \mathrm{~S}$. typhimurium strain SR-11 $\mathrm{Sm}^{\mathrm{R}}$ given intravenously. Vaccination of mice: $\mathrm{X}-\mathrm{X}=$ nonvaccinated; $-\mathrm{C}$ organisms; $\Delta-\Delta=$ ribosomes; $\Delta-\Delta=$ avirulent $S$. typhimurium strain RIA; $\diamond-\diamond=$ virulent $S$. typhimurium strain SR-11. --- = Residual infection with viable $S$. typhimurium strain SR-11 used for immunisation.

immunised with a live vaccine $S$. typhimurium never reached numbers in excess of those observed immediately after challenge. On the other hand, after the initial antibacterial activity observed in mice vaccinated with ribosomal preparations or heat-killed $S$. typhimurium, challenge bacteria multiplied extensively in the liver and a secondary bacteraemia developed. While the numbers of viable organisms did not reach those observed in unvaccinated control animals, mice immunised with either of the nonviable vaccines suffered severe infection as shown by the development of symptoms such as diarrhoea, weight loss, and ruffled fur. Mice vaccinated with the viable preparations failed to develop overt symptoms of infection. 


\section{Discussion}

Plant and Glynn, $(1974,1976)$ reported that inbred strains of mice differ in their native resistance, as measured by LD50 titrations, to a subcutaneous challenge of $S$. typhimurium, whereas we have shown, as did Robson and Vas (1972), little or no variation in LD50 values when genetically different strains were challenged by the intraperitoneal route. However, when the infection was followed by means of other indicators, such as mean time to death and kinetics of bacterial growth in the liver and spleen, real differences in resistance could be discerned. The natural resistance of inbred mice measured in these two ways correlates well with the susceptible or resistant classification presented by Glynn and Plant $(1974,1976)$. Apparent discrepancies in LD50 values, therefore, can be attributed to the different routes of challenge. Intraperitoneal inoculation effectively augmented the virulence of $S$. typhimurium (table II) by providing an environment in which extensive bacterial multiplication could take place (fig. 4A), thereby increasing the challenge dose so that an overwhelming infection ensued (Collins, 1971). This does not happen when infection is initiated by the subcutaneous or intravenous route.

The protection afforded by the ribosomal vaccine correlated well with the susceptibility or resistance pattern exhibited by the individual mouse strains. Outbred Swiss-Cox, A/J, and the hybrids, $\mathrm{C} 3 \mathrm{D}_{2} \mathrm{~F}_{1} / \mathrm{J}$ and $\mathrm{B} 6 \mathrm{D} 2 \mathrm{~F}_{1} / \mathrm{J}$, were fully protected after vaccination whereas strains $\mathrm{C} 3 \mathrm{H} / \mathrm{HeJ}$ and DBA/2J exhibited only partial immunity. Nude (nu/nu), heterozygous Balb/c $(\mathrm{nu} /+)$, strain $\mathrm{C} 57 \mathrm{Bl} / 6 \mathrm{~J}$, and strain $\mathrm{CBA} / \mathrm{J}$ mice did not develop protective immunity. Robson and Vas (1972), using several of these strains, obtained similar results with a phenol-killed $S$. typhimurium vaccine.

Despite the differences in ultimate survival, fewer viable bacteria were recovered from the spleen of all vaccinated mice (protectable or unprotectable) one day after intraperitoneal challenge, than from the spleen of unimmunised mice. As shown with Swiss-Cox and with athymic Balb/c-derived mice, the low counts from the spleen are explained by the rapid killing of the challenge inoculum within the peritoneal cavity of vaccinated animals during the initial hours of infection, thereby effectively reducing the challenge dose and limiting bacterial migration into the systemic circulation. The expression of effective bactericidal activity in the peritoneal cavity of T-cell-deficient athymic mice indicates that it is antibody (B-cell) mediated and is independent of the T-cell-mediated arm of the immune response. The report by Margolis and Bigley (1972) that a cytophilic macroglobulin on the surface of peritoneal macrophages from ribosome-immunised mice facilitates the in-vitro phagocytosis of virulent $S$. typhimurium supports this view. Similarly, cytophilic antibody is present on the surface of peritoneal macrophages of mice immunised with a viable $S$. typhimurium vaccine (Rowley, Turner and Jenkin, 1964; Marecki, Hsu and Mayo, 1975). The ability of specific antibody to effect the killing of $S$. typhimurium by phagocytes within the peritoneal cavity has been demonstrated unequivocally by Collins (1969). Organisms opsonised in vitro with specific immune serum were rapidly phagocytosed and destroyed by 
macrophages after injection into the peritoneal cavity of normal animals. However, this is not protective because systemic $S$. typhimurium infection is delayed but not prevented (Collins, 1969). Similarly, we have shown that early inactivation of a bacterial challenge within the peritoneal cavity of ribosomal vaccine-immunised mice was not sufficient to ensure ultimate survival, because unprotectable strains of mice also exhibited this response. However, the delay in the progression of the infection due to specific opsonising antibody resulted in a significant extension of the MTTD of vaccinated unprotectable mice. Organisms that survived the initial antibody-mediated killing multiplied rapidly within the peritoneal cavity and provided a reservoir for the continuous release of organisms into the systemic circulation. All strains of mice subsequently exhibited a progressive infection characterised by an increase in the number of viable organisms in the spleen between days 1 and 10 after challenge. The only mouse strains that survived the bacterial infection were those that developed an antibacterial response expressed approximately 10 days after challenge, which resulted in the establishment of a low-level chronic infection. Collins (1974) and Davies and Kotlarski (1976) demonstrated that the survival of mice infected with virulent salmonellae depends upon the development of a T-cell-derived specific cell-mediated immune response. Therefore, generation of protective antibacterial activity expressed late in the infection is likely to be the result of a cell-mediated immune response to the antigenic stimulus provided by the viable $S$. typhimurium and not a response to vaccination with the ribosomal preparation. Our observations agree with data obtained with killed whole-cell vaccines (Collins et al., 1966) and by passive transfer of immune serum (Collins, 1969, 1974). Antibody-dependent bactericidal activity within the peritoneal cavity after challenge delays the progression of infection and increases survival time until specific cell-mediated immunity develops in response to the challenge organism. Because the potential for the development of a specific cell-mediated immune response to $S$. typhimurium infection is under genetic control (Plant and Glynn, 1976), ribosome-vaccinated mice of strains genetically incapable of developing such a response succumb to $S$. typhimurium infection despite the presence of opsonic antibodies. However, mice genetically capable of a cell-mediated immune response to $S$. typhimurium have sufficient time to develop protective immunity in response to the challenge infection.

Protective immunity produced by vaccination with the $S$. typhimurium ribosome preparation was compared with that produced by vaccination with heat-killed organisms, living attenuated $S$. typhimurium strain RIA and a sublethal challenge with virulent $S$. typhimurium strain ST-11. A valid comparison of vaccine efficiency requires that the kinetics of infection rather than survival be used as the basis for comparison (Blanden, Mackaness and Collins, 1966; Mackaness et al., 1966). Accordingly, bacterial growth in vaccinated animals challenged intravenously with the virulent SR-11 strain was monitored during a 40-day period. Although Swiss-Cox mice vaccinated with the $S$. typhimurium ribosome preparation or heat-killed organisms survived challenge, they developed a severe infection as indicated by the 
extensive multiplication of infecting organisms in the spleen and liver. Protection produced by ribosomal vaccination, when measured in this manner, was no better than that obtained by immunisation with heat-killed organisms. However, immunisation with living virulent or attenuated organisms prevented any significant increase in the bacterial population during the course of a challenge infection.

The data we present in this report corroborate and extend those of Collins et al. (1966). Although immunisation with killed organisms or ribosomal vaccine may protect mice against lethal infection, bacteria multiply as extensively as in unvaccinated animals. However, mice immunised with living vaccines develop an antibacterial response sufficient to prevent extensive bacterial multiplication and development of a symptomatic infection. Because prevention of clinical infection is a prime criterion in the evaluation of typhoid vaccines in man (Cvjetanovic and Uemura, 1965), a mandatory attribute of an effective vaccine in the mouse-typhoid model should be precisely the same. Clearly, the immunity produced by $S$. typhimurium ribosomal vaccine is not sufficient to prevent multiplication of the infecting bacteria in the organs and tissues and thus is not superior to the protection afforded by killed organisms. Ribosomal vaccines produce a humoral response to surface antigens which are probably co-purified with the ribosomes (Eisenstein, 1975; Hoops et al., 1976; Lieberman, 1977; Misfeldt and Johnson, 1978). However, our observations showed that a ribosomal vaccine failed to induce the required cell-mediated response for protective immunity against mouse typhoid. It appears that the preparation of a subcellular vaccine that can replace living vaccines for induction of the necessary effective cellmediated immunity in mouse or human typhoid is not imminent.

This research was supported by grants (DAAG-29-78-G-0087) from the US Army Research Office, Durham, NC and NIH grant CA22957 from the National Cancer Institute.

\section{REFERENCES}

Ashwell, G. 1957. Colorimetric analysis of sugars. In Methods in enzymology, vol. 3, edited by S. P. Colowick and N. O. Kaplan, Academic Press, New York, p. 73.

Blanden, R. V., Mackaness, G. B. and Collins, F. M. 1966. Mechanisms of acquired resistance in mouse typhoid. J. exp. Med., 124, 585.

Collins, F. M. 1968. Recall of immunity in mice vaccinated with Salmonella enteritidis or Salmonella typhimurium. J. Bact., 95, 2014.

Collins, F. M. 1969. Effect of specific immune mouse serum on the growth of Salmonella enteritidis in nonvaccinated mice challenged by various routes. J. Bact., 97, 667.

Collins, F. M. 1971. Mechanisms in antimicrobial immunity. J. reticuloendothel. Soc., 10, 58.

Collins, F. M. 1972. Effect of adjuvant on immunogenicity of a heat-killed salmonella vaccine. J. infect. Dis., 126, 69.

Collins, F. M. 1973. Immunogenicity of living and heat-killed Salmonella pullorum vaccines. Infect. Immun., 7, 735.

Collins, F. M. 1974. Vaccines and cell-mediated immunity. Bact. Rev., 38, 371.

Collins, F. M., Mackaness, G. B. and Blanden, R. V. 1966. Infection-immunity in experimental salmonellosis. J. exp. Med., 124, 601.

Cvjetanovic, B. AND Uemura, K. 1965. The present status of field and laboratory studies of typhoid and paratyphoid vaccines. Bull.Wld Hlth Org., 32, 29. 
DAVIES, R. AND KoTLARSKI, I. 1976. The role of thymus-derived cells in immunity to salmonella infection. Aust. J. exp. Biol. med. Sci., 54, 221.

Dische, Z., 1955. Color reactions of nucleic acid components, p. 285-306. In The nucleic acids, vol. 1, chemistry and biology, edited by E. Chargaff and J. N. Davidson, Academic Press, New York.

EISENSTEIN, T. K. 1975. Evidence for O antigens as the antigenic determinants in "ribosomal" vaccines prepared from Salmonella. Infect. Immun., 12, 364.

GERMANIER, R. 1972. Immunity in experimental salmonellosis. III. Comparative immunization with viable and heat-inactivated cells of Salmonella typhimurium. Infect. Immun., 5, 792.

Hobson, D. 1957. Resistance to reinfection in experimental mouse typhoid. J. Hyg., Camb., 55, 334.

Hoops, P., Prather, N. E., Berry, L. J. and Ravel, J. M. 1976. Evidence for an extrinsic immunogen in effective ribosomal vaccines from Salmonella typhimurium. Infect. Immun., $13,1184$.

JENKIN, C. R. AND RowLEY, D. 1963. Basis for immunity to typhoid in mice and the question of "cellular immunity". Bact. Rev., 27, 391.

JoHNSON, W. 1972. Ribosomal vaccines. I. Immunogenicity of ribosomal fractions isolated from Salmonella typhimurium and Yersinia pestis. Infect. Immun., 5, 947.

JoHnson, W. 1973. Ribosomal vaccines. II. Specificity of the immune response to ribosomal ribonucleic acid and protein isolated from Salmonella typhimurium. Infect. Immun., 8, 395.

LIEBERMAN, M. M. 1977. Direct evidence for the presence of lipopolysaccharide components in a Pseudomonas ribosomal vaccine. Infect. Immun., 17, 471 .

LIN, J.-H. AND BERRY L. J. 1978. The use of strain LT2-M1 in identifying the protective antigens in a Salmonella typhimurium-derived ribosomal vaccine. J. reticuloendothel. Soc., 23, 135.

Lowry, O. H., Rosebrough, N. J., Farr, A. L. And Randoll, R. J. 1951. Protein measurement with the Folin phenol reagent. J. biol. Chem., 193, 265.

MaCKaness, G. B., Blanden, R. V. AND Collins, F. M. 1966. Host-parasite relations in mouse typhoid. J. exp. Med., 124, 573.

MareCKI, N. M., Hsu, H. S. AND Mayo, D. R. 1975. Cellular and humoral aspects of host resistance in murine salmonellosis. Br. J. exp. Path., 56, 231.

Margolis, J. M. AND Bigley, N. J. 1972. Cytophilic macroglobulin reactive with bacterial protein in mice immunized with ribonucleic acid-protein fractions of virulent Salmonella typhimurium. Infect. Immun., 6, 390.

Medina, S., VAS, S. I. AND RoBson, H. G. 1975. Effect of nonspecific stimulation on the defense mechanisms of inbred mice. J. Immun., 114, 1720.

MiSFELDT, M. L. AND JOHNSON, W. 1976. Variability of protection in inbred mice induced by a ribosomal vaccine prepared from Salmonella typhimurium. Infect. Immun., 14, 652.

MiSFELDT, M. L. AND JOHNSON, W. 1978. Identification of protective cell surface proteins in ribosomal fractions from Salmonella typhimurium. Infect. Immun., 24, 808.

Mitsuhashi, S., Kawakami, M., Yamaguchi, Y. And NagaI, M. 1958. Studies on the experimental typhoid. I. A comparative study of living and killed vaccines against the infection of mice with S. enteritidis. Jap. J. exp. Med., 28, 249.

Nickol, A. D. AND Bonventre, P. F. 1977. Anomalous high native resistance of athymic mice to bacterial pathogens. Infect. Immun., 18, 636.

Plant, J. AND GlynN A. A. 1974 . Natural resistance to Salmonella infection, delayed hypersensitivity and Ir genes in different strains of mice. Nature, Lond., 248, 345.

Plant, J. and Glynn, A. A. 1976. Genetics of resistance to infection with Salmonella typhimurium in mice. J. infect. Dis., 133, 72.

ReED, L. J. AND MUENCH, H. 1938. A simple method of estimating fifty per cent endpoints. Am. J. Hyg., 27, 493.

RobSON, H. G. AND VAS, S. I. 1972. Resistance of inbred mice to Salmonella typhimurium. J. infect. Dis., 126, 378. 
Rowley, D., TuRner, K. J. AND Jenkin, C. R. 1964. The basis for immunity to mouse typhoid. 3. Cell-bound antibody. Aust. J. exp. Biol. med. Sci., 42, 237.

Smith, R. A. AND BIGLEY, N. J. 1972. Detection of delayed hypersensitivity in mice injected with ribonucleic acid-protein fractions of Salmonella typhimurium. Infect. Immun., 6, 384.

Ushiba, D., Saito, K., Akiyama, T., Nakano, M., Sugiyama, T. and Shirono, S. 1959. Studies on experimental typhoid: bacterial multiplication and host cell response after infection with Salmonella enteritidis in mice immunized with live and killed vaccines. Jap. J. Microbiol., 3, 231.

VenNeman, M. R. AND BerRy, L. J. 1971a. Serum-mediated resistance induced with immunogenic preparations of Salmonella typhimurium. Infect. Immun., 4, 374.

Venneman, M. R. AND BerRy, L. J. 1971 $b$. Cell-mediated resistance induced with immunogenic preparations of Salmonella typhimurium. Infect. Immun., 4, 381.

VENNEMAN, M. R. AND Bigley, N. J. 1969. Isolation and partial characterization of an immunogenic moiety obtained from Salmonella typhimurium. J. Bact., 100, 140.

VenNeman, M. R., Bigley, N. J. AND BERRY, L. J. 1970. Immunogenicity of ribonucleic acid preparations obtained from Salmonella typhimurium. Infect. Immun., 1, 574. 